\title{
AC 2011-1226: PROGRESS REPORT - THE DEVELOPMENT OF HIGH PERFORMANCE CAPSTONE PROJECT TEAMS AND THE SELECTION PROCESS
}

\section{Stephen W. Laguette, University of California, Santa Barbara}

Stephen Laguette is currently a Lecturer at the University of California, Santa Barbara in the College of Engineering in the Department of Mechanical Engineering (ME) and the Technology Management Program and is responsible for the undergraduate ME Capstone Design program. He received his BS, MS in ME from the University of California, Los Angeles. His professional career has included executive Research and Development management positions with a number of medical device companies. He has been responsible for the creation of complex medical devices with over fifteen US patents issued in a variety of surgical fields. He has been responsible for the identification of new technologies and the review of new business opportunities. His responsibilities have included transitioning projects into development and potential commercialization. He has identified and successfully created research programs with leading academic institutions and formed strategic alliances with other high technology companies. He is currently serving as a Director with the Design in Engineering Education Division (DEED) for the American Society of Engineering Education (ASEE). His academic interests include Capstone design and the development of high performance student teams. He also remains active in the field of medical devices as a consultant for new ventures and investment firms.

(c)American Society for Engineering Education, 2011 


\title{
Progress Report - The Development of High Performance Capstone Project Teams and the Selection Process
}

\begin{abstract}
The development of high performance Capstone project teams and the team formation process has previously been reported ${ }^{1}$ but only provided information regarding initial experience and did not include year-end student project results. This paper is intended to provide a more complete report of the results and the continued evolution of the process and the design program.

A successful Capstone Design program including companion design courses has been developed $^{2,3}$ that has become an integral and important component of the Mechanical Engineering curriculum. A variety of challenging projects are created each year to appeal to student academic and career interests. Students work in teams with the assistance of a faculty advisor to tackle a significant mechanical engineering design project. The formation of student teams can be a challenging and time consuming process that is critical to the success of the design project and the course experience. Attention continues to be focused upon the formation of student teams and the selection process in the hopes of developing high performance student teams.
\end{abstract}

Successful student teams should include enthusiastic, motivated and engaged students as they must address the project over the academic year of the Fall, Winter and Spring quarters. The student team should also include satisfactory skills, technical or academic expertise required for each project. As previously reported ${ }^{1}$, by including student preferences in the team formation process and careful assessment of student strengths and weaknesses, the development of a high performance Capstone project team may be more likely to occur.

This paper will address the experiences and the continued evolution of project team formation and the student selection process. It has now evolved to include an online process that allows the student to identify individual preferred project selections. The process also includes the ability to capture individual student academic and career interests as well as the expertise that may be offered towards the project and team.

Typical class size is between 68 and 110 senior ME students resulting in 14 to 22 projects and teams each year. The Capstone projects include Industry Partnered, Research Partnered, Student Competitions, and Independently created projects. The Capstone projects reflect the technical expertise of the department and faculty including solid mechanics, structures, materials, dynamics, systems and control, robotics, fluid mechanics, thermal sciences, computational science, and nanotechnology. Projects are created each year that vary in the type and the level of technical challenges to be addressed by the student teams.

This selection and team formation process has created a positive environment for high performance teams to flourish. A summary of the first year of experience and the in-progress results for the second year will be presented. 


\section{Introduction}

Although there is great deal of published business and management literature regarding high performance teams, a review of the published literature indicates that little attention has been given to the development of high performance Capstone Design student project teams. Attention in the academic environment has been focused solely on team formation including random assignment, automating processes, algorithms, and methodologies ${ }^{4,5,6,7,8}$. The characteristics of "good' student teams and assessments have been presented ${ }^{9,10}$ but provide little guidance. A function-based approach has been introduced in terms of team member selection and qualitative assessment $^{11,12}$ with no quantitative results presented.

An attempt has been made to create students teams that should be more engaged and motivated based upon student project preferences. Additional efforts have been incorporated to ensure a proper mix of skills and expertise with mutual accountability among the student team members. As previously reported ${ }^{1}$, an online process of student project selections has been developed that is coupled with self-assessment forms and proposed team submittals. Initial experience with this process yielded a 97\% overall success rate in meeting at least one of three student preferences and a $67 \%$ success rate in meeting the student's first preference regarding project selection. Approximately 50\% of the teams going forward were proposed by the students (Student Formed) with some assigned team members. Approximately 50\% of the teams were created by the course instructor (Instructor Formed) with assignment based upon the complete process.

The project selection and team selection process has previously been described in greater detail ${ }^{1}$. This paper will focus upon further observations and a review of the results of this process.

The process resulted in the preliminary identification by independent faculty review of four high performance teams prior to project completion. All four teams were Student Formed through the student team submittal process including the addition of students to the teams by the instructor. This paper will provide further examination of these four teams now that the projects have been completed.

Preliminary results prior to projects completion also indicated that team self satisfaction appeared to be very good and team performance appeared to be very good overall for all teams. It was also noted that overall student satisfaction, the absence of significant team conflicts and the elimination of dysfunctional teams may also be important observations. This paper will address these observations now that the projects have been completed.

\section{High Performance Teams}

A simple and effective description of a project team has been defined ${ }^{12}$ and is applicable for the approach under consideration:

"A team is a small number of people with complementary skills who are committed to a common purpose, performance goals, and approach for which they hold themselves mutually accountable." 
Using this definition, the driving factors for all project teams have also been described as follows ${ }^{13,14}$ :

- All teams need a sense of purpose and a clear cut mission.

- All teams need the mission to be broken down into meaningful performance goals for each team member to pursue.

- All teams need to develop certain work approaches, procedures and processes to ensure that they accomplish a task efficiently and effectively.

- All teams have to support the common mission and take their individual responsibility seriously to do their part in accomplishing a task.

- All teams need a mix of skills, experience, and expertise, in order to meet the challenges of the team task.

To further differentiate the qualities of high performance team ${ }^{12,13}$ as compared with average teams:

- A deeper sense of purpose

- Relatively more ambitious performance goals

- Better work approaches and outcomes

- Mutual accountability

- Complementary skills and expertise

Based upon these understandings, if the driving factors for all teams and the qualities of a high performance team are desirable for a student Capstone project team, randomly assigning students is clearly inappropriate and must be avoided. By including student preferences in the team formation process and careful assessment of student strengths and weaknesses, the development of a high performance Capstone project team may be more likely to occur.

\section{Team Dysfunction}

Prior experience with student team formation had resulted in some problematic teams and has included:

- A team with no fabrication experience and no desire to actually build their project

- Some teams that have lacked the proper level of technical expertise

- Some teams that were a group of friends or roommates with poor motivation and work processes that resulted in poor performance

- A team that revolted over a dictatorial team leader with a near altercation

The preliminary results that were previously reported ${ }^{1}$ with the current process of team formation noted an observation regarding the absence of dysfunctional teams in terms of performance and team dynamics. However no clear definition of team dysfunction was previously presented. 
A popular description of the five dysfunctions of a team has been described ${ }^{15}$ :

- Absence of trust

- Fear of conflict

- Lack of commitment

- Avoidance of accountability

- Inattention to results

Although these actions may clearly impact team performance and team dynamics, they are more descriptive of "under performing" teams as opposed to a dysfunctional team in the context of Capstone design teams. For the purpose of this paper, a dysfunctional team is a team that is prevented from performing or completing expected activities due to conflict or behavior on the team by one or more team members. This should be evident by assessment of poor team dynamics and poor overall team performance in terms of project and course deliverables.

\section{Student Project Selection}

The incoming senior students are aware that the project list will be posted prior to the start of school and are also alerted by email. The students may identify and select their top three preferences. An online process has been created and may be accessed from the course web site. This online process is limited to enrolled students and is password controlled. The selection table provides a link for each project name to the project description.

The students are not guaranteed to be placed onto a team within their top three preferences.

\section{Team Selection}

The final team selection process is completed during the second week of school. The students have been required to provide their top three project preferences and a self assessment form for accountability. Interested students have also proposed their own teams for consideration. In addition to the provided student information, a review of academic records is conducted by the instructor to better ensure that student expertise matches the expected technical challenges for their project selections.

The students may also propose their own project team based upon the online student selections. The online process allows visibility for all interested students. The students may propose a team with a minimum of three and a maximum of five team members. They are advised that proposed teams with less than five members may have students added to the team by the instructor.

The students are advised at the start of the course that to excel, they must excel as a team. Individual performance alone will not be satisfactory. Due to the complexities of the projects and the complexities of the course deliverables, only high performing functional teams will excel.

Average teams in terms of performance will reflect average grades. Dysfunctional teams will be problematic and will encounter difficulties in meeting the course deliverables and project deliverables. 
The student teams are responsible for completing their engineering efforts each quarter and ultimately completing their project. These engineering efforts are generally characterized for the students as Prototyping, Testing, Modeling and Analysis for the purposes of the academic course experience.

The focus for final team selection is a proper mix of student skills, experience, and expertise, in order to meet the expected challenges of the engineering efforts. The team members should have identified a preference for the expected project challenges, possess the necessary skills, and have been made accountable for their roles and responsibilities in terms of Prototyping, Testing, Modeling, and Analysis.

\section{Results}

The 2009/2010 academic year was the first year that has incorporated a mandatory online project selection process, use of self assessment, required team skills for engineering efforts and review of academic records for final team selections. The 2010/11 academic year used the same selection process. The results of student placement regarding the student preferences may be reviewed in Table 1. The results of team formation may be reviewed in Table 2.

\begin{tabular}{|l|c|c|c|c|c|c|}
\hline Year & Total Students & $\begin{array}{c}\text { Total } \\
\text { Teams }\end{array}$ & $\begin{array}{c}\text { Total 1st } \\
\text { preference }\end{array}$ & $\begin{array}{c}\text { Total 2nd } \\
\text { preference }\end{array}$ & $\begin{array}{c}\text { Total 3rd } \\
\text { preference }\end{array}$ & $\begin{array}{c}\text { Total } \\
\text { preferred } \\
\text { placement }\end{array}$ \\
\hline $2009 / 10$ & 73 & 15 & $49(67 \%)$ & $10(14 \%)$ & $12(16 \%)$ & $71(97 \%)$ \\
\hline $2010 / 11$ & 68 & 14 & $52(76 \%)$ & $12(18 \%)$ & $1(2 \%)$ & $65(96 \%)$ \\
\hline
\end{tabular}

Table 1. Student Placement Results

\begin{tabular}{|l|c|c|c|}
\hline Year & Total Teams & Student Formed & Instructor Formed \\
\hline $2009 / 10$ & 15 & $7(47 \%)$ & $8(53 \%)$ \\
\hline $2010 / 11$ & 14 & $8(57 \%)$ & $6(43 \%)$ \\
\hline
\end{tabular}

Table 2. Team Formation Results

The selection process continued to be very successful with 71 of 73 (97\%) the first year and 65 of 68 (96\%) of students being placed on a preferred project selection. It should also be noted that $67 \%$ of students were placed with their first selection the first year and $76 \%$ the following year. No students requested a change of placement.

The students are allowed to also propose their own teams with the understanding that the team should have a complementary mix of skills, experience, and expertise to meet the anticipated challenges presented by the selected projects. A team submittal needed to have a minimum of three members with the understanding that additional members may then be added. Results for both years indicate that approximately $50 \%$ of the teams are formed by the students with the understanding that additional students may be added. 
The entire process of review and team determinations was completed during the second week of the quarter. It is estimated that this process required about 20 hours of instructor time. Time is needed to review all forms, ensure a proper mix of skills and expertise, and academic reviews once the teams are somewhat defined.

In addition to Self Assessment forms, a Team Survey was administered for the 2009/10 students at the end of the Fall, Winter and Spring quarters to assess their team dynamics and performance. Team and self satisfaction appeared to be very good for all teams and students based upon the assessments and surveys. There were no observed team conflicts. All teams indicated that they enjoyed working together and that there was a positive atmosphere on the team.

A Design Review is conducted for all projects and teams as part of the course requirements during the Winter quarter. Design Reviews are attended by three independent faculty members not involved in the team selection process. These faculty provide a scoring for all reviews in terms of the quality of the Design Review, team dynamics, project activities, and the quality of designs. Additionally these faculty were asked to identify perceived high performance teams with a simple Team Assessment scoring rubric. The reviewers were unanimous in their selection of four 2009/10 teams. The Design reviews have not yet been conducted for the 2010/11 teams and high performance teams have not yet been identified.

All four identified 2009/10 high performance teams were originally Student Formed through the student team submittal process. Two of these teams were submitted with five students and no students were added to the team. One team was submitted with four students and one student was added. One team was submitted with three students and two students were added to the team. Three of the four projects were Industry partnered.

The four identified high performance teams were the following:

- an aerospace Industry partnered hinge deployment mechanism project (Figure 1)

- a medical device supplier Industry partnered material dispenser system project (Figure 2)

- a medical device implant Industry partnered surgical instrument project (Figure 3)

- a student Engineers Without Borders water chlorination project (Figure 4) 


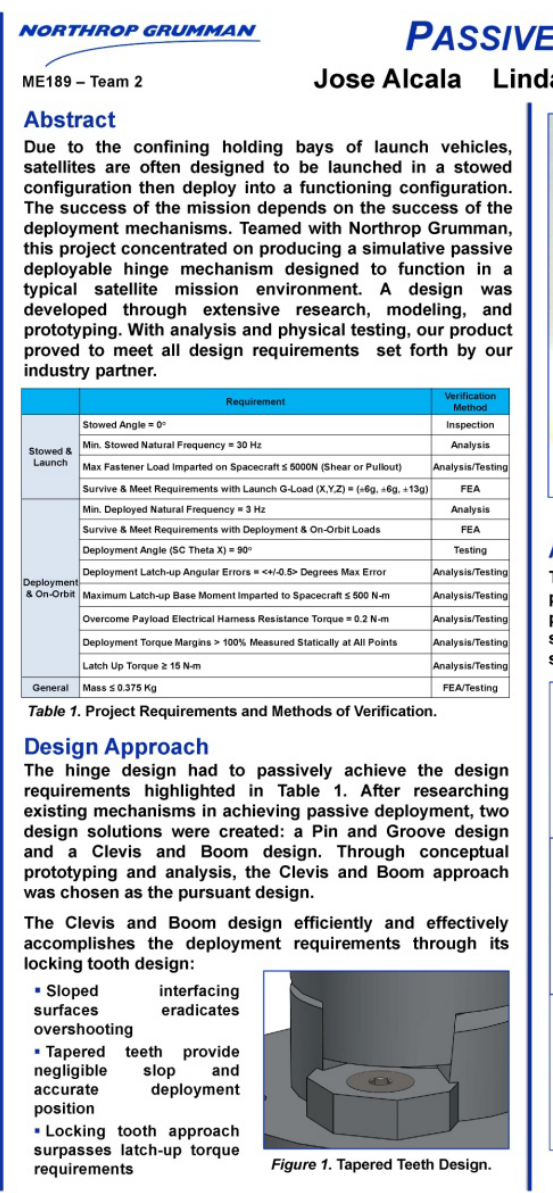

DEPLOYABLE HINGE MECHA
Allen Francisco Ayala Wil Haynes

UC SANTA BARBARA engineering June 4, 2010

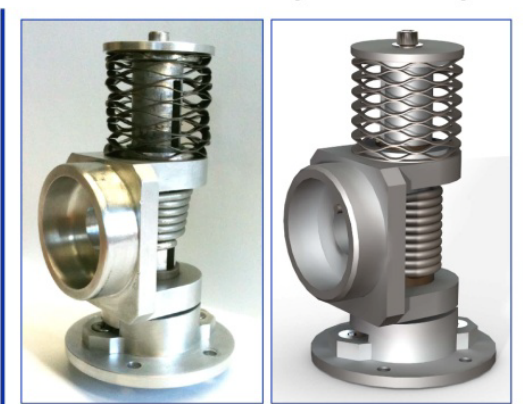

Figure 2. Prototype Model (left) and Solidworks CAD Model (right).

Analysis

The hinge was modeled using SolidWorks and FEA was performed using COSMOS. Models precisely emulating the physical hinge were developed and launch loads,
stowed/deployed loads, and on-orbit loads were applied to simulate actual launch and deployment conditions.

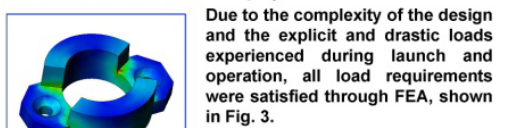
satisfied through $F E A$, shents in Fig. 3.

Energy calculations were utilized in the sizing of springs during the design phase and also used to compliment dynamic physical testing. Vibration analysis was frequency requirements.
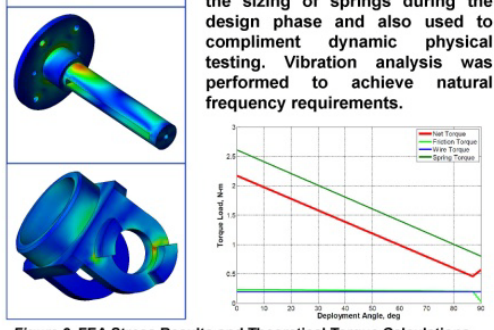

Figure 3. FEA Stress Results and Theoretical Torque Calculations.

David Murphy*

June 4,2010

Testing

In order to properly test our design, a test bench was and mass while maintaining their inertial effects. With this test bench, a series of tests were performed that determined the static and dynamic attributes of the hinge.

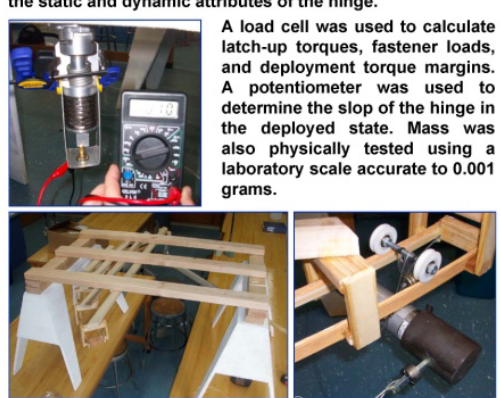

Figure 4. Angular Slop Test (top) and Test Bench Set-up (bottom).

Results

Through the testing and analysis performed, we confidently met all requirements. The overall mass was found to be 8 grams under the maximum, torque margins were determined to well exceed the minimum requirements, fastener loads and latch-up base moments were significantly lower than specified, and all margins of safety were positive.

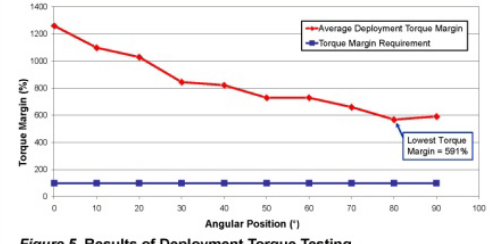

Figure 5. Results of Deployment Torque Testing.

Acknowledgments

Robert Leedom Prof. Kedward Prof. Kedward
Prof. Laguette

Nicole Holstrom Andy Weinberg

Figure 1. Aerospace Industry partnered hinge deployment mechanism project 


\section{A5GAPPLEDSLLCONE Mix Meter Dispensing System d engineering \\ Nolan Pasko · John Heineken · Adrian Basharain · Zuhair Hasan · Trung Le ME189-10 June $4^{\text {th }} 2010$}

\section{Abstract}

Silicone breast prostheses are made from a two part ilicone oils mixed at 1:1 ratio by weight. Upon mixing and cooking this mixture the molecules crosslink creating a non-flowable gel. This is necessary to prevent silicone from seeping into body tissue if the prostatic membrane were to rupture. Currently these oils are measured, mixed, and injected by hand. This process is labor intensive and prone to human error which can result in expensive wasted material. This goal of this project was to create an automated device to improve mixing accuracy, reduce processing time, eliminate the need for skilled labor, and decrease material waste of the breast prosthesis manufacturing process.
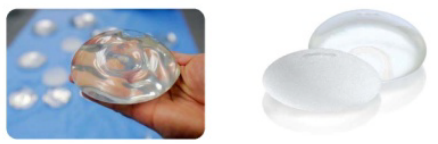

Figure 1. Caption in Arial, 28 points, bold.

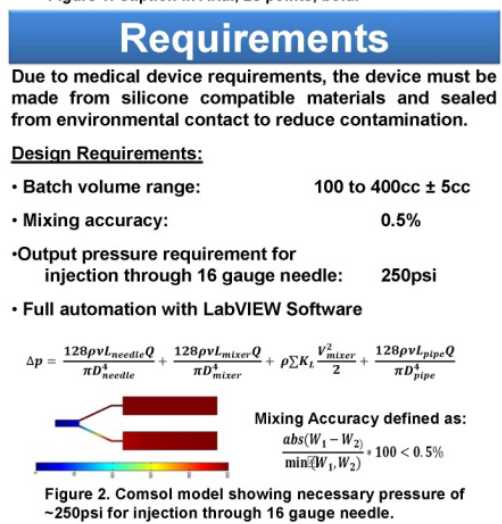

\section{Requirements} from environmental contact to reduce contamination.

-Output pressure requirement for

IIl automation with LabVIEW Software

\section{Design Evolution}

The device operates by filling two hydraulic cylinder sequentially with Part A and Part B silicone oils. Linear transducers meter the cylinder volumes while differentia weight measurements taken throughout the process verify that the mixing accuracy is met. After verification, the actuator forces the silicone oils simultaneously through a static mixer.

After initially proving the ability to infer weight of the cylinder contents, we proved the feasibility of using single load cell for both cylinders, while providing the necessary accuracies. This reduced cost, minimized error due to calibration, but forced the process to fill each due to calibration, but forced the process to fill each
cylinder sequentially 13 3 increaseing cycle time.

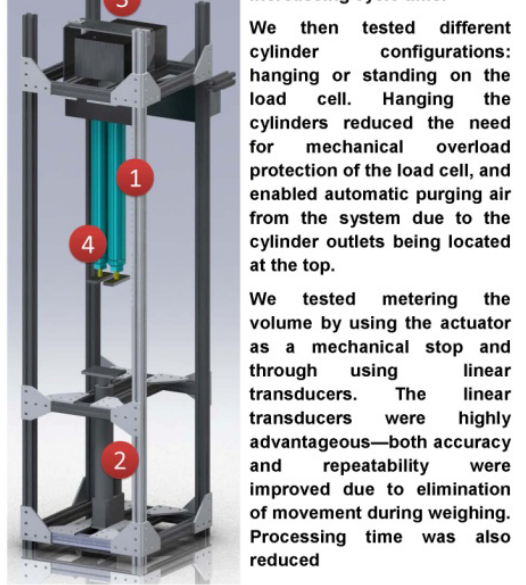

Figure 3. CAD Rendering of Prototype (1) Weighing Cylinders (2) Actuator (3) Load Cell (4) Linear Transducers

\section{Testing Results}

We performed extensive preliminary testing that proved with a single load cell, either standing or hanging. Preliminary tests showed that accurate metering was possible through using the actuator as a piston stop during filling. In the final prototype this method proved inconsistent and linear transducers were adopted for metering purposes. Figure 4 shows that the mixing ratio error was consistently below $0.5 \%$ over the range of 100 to $400 \mathrm{cc}$. Final Volumes were within the requirement of $\pm 5 \mathrm{cc}$

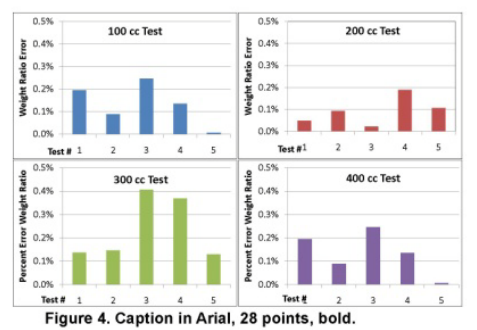

The final prototype underwent a pressure test where the system was pressurized and we inspected for leaks. sys presence of leaks. The results can be seen in Figure 5 .

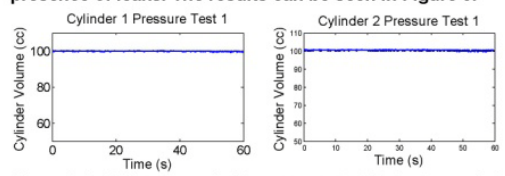

Figure 5. Cylinder volume during pressure test, indicating no leaks Acknowledgments

Applied Silicone, Alastair Winn, Stephen Laguette

Munson, Bruce R., Donald F. Young, and Theodore H. Okiishi. "Fundamentals of Fluid Mechanics." Fifth Edition

Figure 2. Medical device supplier Industry partnered material dispenser system project 


\section{Adjustable DTS guide for ACDF surgical procedure}

\section{CiNUVASIVE: Andrew Pado, Ryan Pawell, Keith Schetne, Brett Smith, Sarah Stoltz, Wesley Thibault}

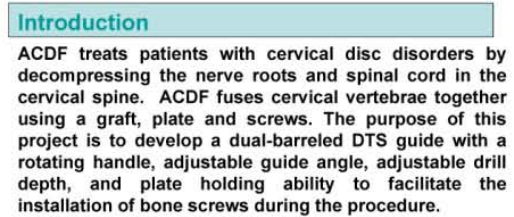

ACDF treats patients with cervical disc disorders by decompressing the nerve roots and spinal cord in the cervical spine. ACDF fuses cervical vertebrae together using a graft, plate and screws. The purpose of this project is to develop a dual-barreled DTS guide with a rotating handle, adjustable guide angle, adjustable drill depth, and plate holding ability to facilitate the installation of bone screws during the procedure.
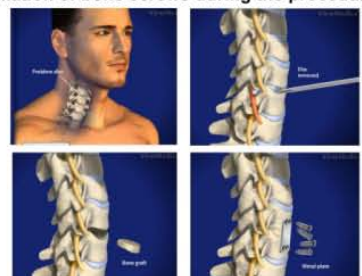

Figure 1. Anterior Cervical Discectomy and Fusion Procedur

\section{Design Development}

The team travelled down to the NuVasive cadaver lab to obtain a surgeon's perspective of the procedure. This hands on experience furthered our understanding of the surgeons limited work space and need for on-the-fly, adjustable mechanisms. The cadaver lab visit resulte in major design changes shown in the first round of rapid prototypes.

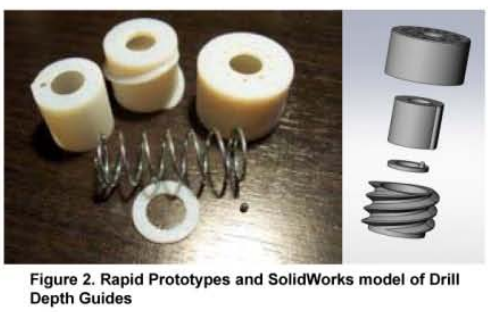

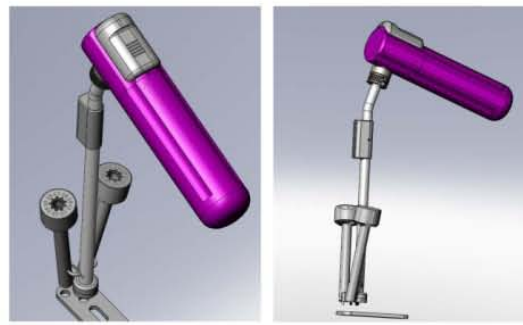

Figure 3. Complete SolidWorks model of DTS guide

\section{Engineering Challenges}

Each mechanism evolved over a series of design iterations. In order to maximize effectiveness and minimize tissue damage the DTS guide must be compact and intulive. This resulted in multiple modeling and manufacturing challenges because three mechanisms were integrat The stainless steel shaft. The small incrementation resulted in high precision machining and manufacturing. Lastly, micro TIG welding was their precise assemble the small parts without altering

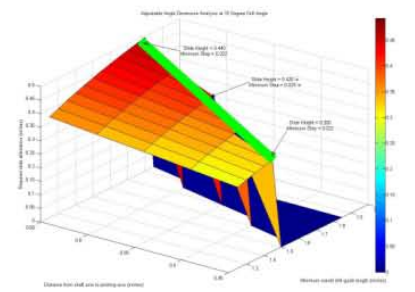

Figure 4. MATLAB plot for determining incrementation for the Angle Rotation mechanism

\section{Results}

A functional stainless steel prototype was made and tested. Thirteen out of the fourteen performance requirements were met by analyzing the orientation structural and surgical capabilities of the DTS guide. Due to limited budget the team chose not to get the Drill Depth Guides machined and rather, functional rapid prototypes were made. All other mechanisms however, were machined and implemented in the fina prototype.
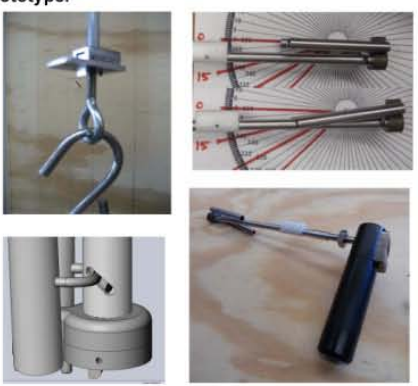

Figure 5. Prototyping, testing, modeling and analysis

\section{Conclusion}

In conclusion our design efforts resulted in a functional proof of concept, however this device is not surgeryready. Our deliverables also include a complete comprehensive test reports and $3 \mathrm{D}$ model package.

\begin{tabular}{|ll|}
\hline Acknowledgments & \\
\hline Shaeffer Bannigan & Nicole Holstrom \\
Dave Bothman & Stephen Laguette \\
Michael Brotman & Kamala McNaul \\
Ryan Donahoe & Andy Weinberg \\
Kirk Fields & \\
\hline
\end{tabular}

Figure 3. Medical device implant Industry partnered surgical instrument project 


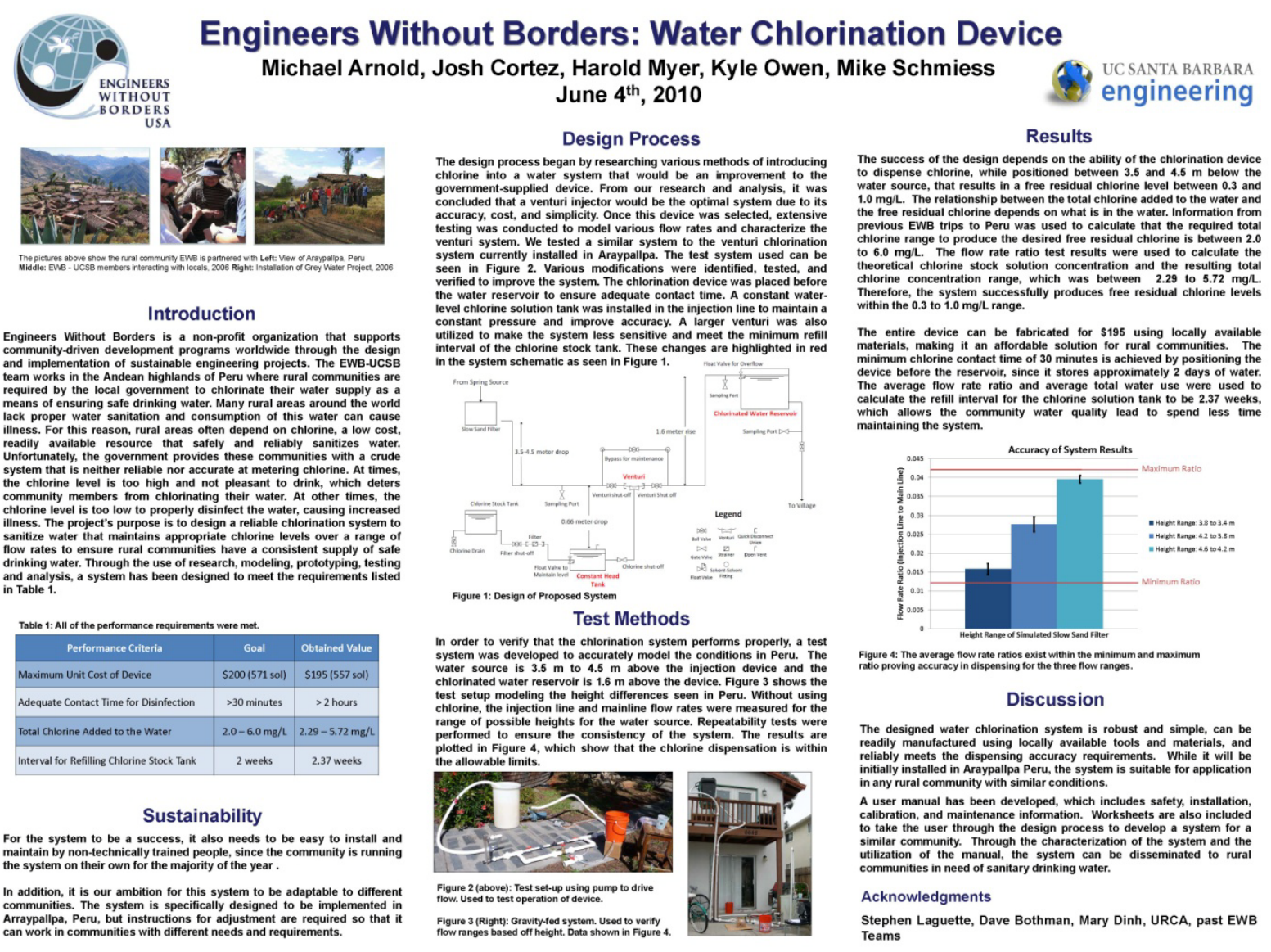

Figure 4. Student Engineers Without Borders water chlorination project

The four identified high performance teams continued their performance through the completion of the course deliverables and project completion. A year-end poster competition event is held every June to celebrate the completion of the projects. A team of judges comprised of independent faculty and independent industry executives select the Most Innovative Design, Most Marketable Design, and Best Technical Presentation posters at the event. The hinge deployment mechanism and water chlorination projects were selected for awards. The team leader for the material dispenser project was later hired after graduation by the Industry partner and has been instrumental in the eventual commercial release of this system. The surgical instrument project was recognized by its Industry partner for its innovative design features. All four teams received excellent course grades.

A review of team and self assessments for the high performance teams indicates a high degree of team and self satisfaction. Recall that all four teams were formed through student team submittal. Two of the four teams were proposed with all five team members. Team and self satisfaction were very high for these teams. Two of the four teams did require that students were added. A review of year end assessments indicates that one of the added students on each of these teams was never fully integrated in terms of team dynamics. Self satisfaction by these students was 
high but peer assessments indicated less than expected performance was demonstrated. It appears that these teams set high expectations for all team members which were not met by the added members.

The selection process and team formation process did not eliminate under performing teams in spite of meeting student project preferences. There were two 2009/10 teams that under performed in terms of year end course deliverables and project deliverables. Both of these teams were Industry partnered and Instructor Formed using student project preferences. A review of these teams indicates that both had very weak team leaders in terms of technical expertise and leadership skills. These teams clearly stumbled in terms of completing their projects. There were no team conflicts observed but team satisfaction scores were noticeably lower than the high performance teams. These under performing teams were, however, not dysfunctional per the previously stated criteria of team conflict or behavior impacting performance. It appears that these teams simply did not put forth the effort to complete their work.

\section{Conclusions}

An online process of student project selections has been developed that is coupled with selfassessment forms and proposed team submittals. This process with two years of experience has yielded over 95\% overall success rate in meeting at least one of three student project preferences and a $70 \%$ success rate in meeting the student's first preference. Approximately $50 \%$ of the teams going forward were Student Formed with possible assigned team members added. Approximately 50\% of the teams were Instructor Formed with assignment based upon the complete process.

No students requested reassignment and no student were reassigned after team formation. The process has resulted in overall satisfaction in terms of team performance and team dynamics by all teams and all students as captured through student Self Assessments and Team Surveys. The online process is clearly successful in forming teams and should be maintained.

The process resulted in four high performance teams. Three of the four teams were Industry partnered. All four teams were Student Formed through the student team submittal process. However, students were added to two of the teams. Some of these added students were never fully integrated into the team in terms of perceived performance and team dynamics.

There were two under performing teams. Both teams were Industry partnered and both Instructor Formed. These teams could not be characterized as dysfunctional due to the absence of observed team conflict or behavior impacting performance. They suffered from weak team leadership, poor individual and team performance in terms of course and project deliverables.

An attempt has been made to create students teams that should be more engaged and motivated based upon student project preferences. Additional efforts have been incorporated to ensure a proper mix of skills and expertise with mutual accountability among the student team members. Team self satisfaction appears to be very good and team performance appears to be very good overall. The overall student satisfaction, the absence of significant team conflicts and the 
elimination of dysfunctional teams may also be important observations but does not eliminate under performing teams.

\section{Bibliography}

1. Laguette, Stephen W. The Development of High Performance Capstone Project Teams and the Selection Process. Proceedings of the 2010 ASEE Annual Conference \& Exposition.

2. Laguette, Stephen W. Development of a Capstone Design Program for Undergraduate Mechanical Engineering. Proceedings of the 2007 ASEE Annual Conference \& Exposition.

3. Laguette, Stephen W. Integration of Industry Partners into a Capstone Design Program. Proceedings of the 2008 ASEE Annual Conference \& Exposition.

4. Conley, Edgar. On Designating Student Design Teams. Texas Tech University, CISER Conference, Poster, Feb 2008.

5. Lasher, William C. and Ford, Ralph M. Workshop - Effective Practices for Team Formation and Faculty Involvement in Capstone Design Courses. $38^{\text {th }}$ ASEE/ISEE Frontiers in Education Conference. October 2008.

6. Cavanaugh, Ryan et al. Automating the Process of Assigning Students to Cooperative-Learning Teams. Proceedings of the 2004 ASEE Annual Conference \& Exposition.

7. Freiheit, Theodor and Wood, Julian. An Algorithm for Project Assignment in Capstone Design. Proceedings of the 2007 ASEE Annual Conference \& Exposition.

8. Jack, Hugh. A Methodology for Assigning Project Teams. Proceedings of the 2007 ASEE Annual Conference \& Exposition.

9. Bannerot, Richard. Characteristics of Good Teams. Proceedings of the 2005 ASEE Annual Conference \& Exposition.

10. Shaeiwitz, Joseph A. Observations on Forming Teams and Assessing Teamwork. Proceedings of the 2003 ASEE Annual Conference \& Exposition.

11. Sauer, Sharon and Arce, Pedro E. Team Member Selection: A Functional-Based Approach. Proceedings of the 2004 ASEE Annual Conference \& Exposition.

12. Sauer, Sharon and Arce. Pedro E. Development, Implementation, and Assessment of High Performance Learning Environments. Proceedings of the 2003 ASEE Annual Conference \& Exposition.

13. Katzenbach, Jon R. and Smith, Douglas K. The Wisdom of Teams: Creating the High Performance Organization. Boston: Harvard Business School Press, 1993

14. Katzenbach, Jon R. and Smith, Douglas K. The Discipline of Teams. Boston: Harvard Business School Press, 1993

15. Lencioni, Patrick. The Five Dysfunctions of a Team. Jossey-Bass, 2002 